\title{
Effect of Positive Airway Pressure Therapy on Seizure Control in Patients with Epilepsy and Obstructive Sleep Apnea
}

\author{
An Expert Interview with Thapanee Somboon
}

Sleep Disorders and Epilepsy Centers, Neurological Institute, Cleveland Clinic, Cleveland, $\mathrm{OH}, \mathrm{US}$

DOl: https://doi.org/10.17925/USN.2018.14.1.25

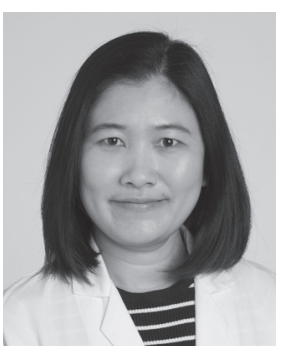

Thapanee Somboon

Thapanee Somboon, $\mathrm{MD}$, is a research fellow in sleep medicine at the Cleveland Clinic, $\mathrm{OH}$, mentored by Nancy Foldvary-Schaefer. She received her medical degree and trained in neurology at the Prince of Songkla University, Songkhla, and trained in clinical epilepsy at

Prasat Neurological Institute, Bangkok, both in Thailand.

\section{Keywords}

Epilepsy, obstructive sleep apnea, positive airway pressure (PAP) therapy, seizure control

Disclosure: Thapanee Somboon has nothing to declare in relation to this article.

Review Process: This is an expert interview and as such, has not undergone the journal's standard peer review process.

Authorship: The named author meets the International Committee of Medical Journal Editors (ICMJE) criteria for authorship of this manuscript, takes responsibility for the integrity of the work as a whole, and has given final approval for the version to be published.

Open Access: This article is published under the Creative Commons Attribution Noncommercial License, which permits any noncommercial use, distribution, adaptation, and reproduction provided the original author and source are given appropriate credit. (c) The Author 2018

Received: December 21, 2017

Published Online: February 16, 2018

Citation: US Neurology. 2018;14(1):25-26

Corresponding Author: Thapanee Somboon, Sleep Disorders and Epilepsy Centers, Neurological Institute, Cleveland Clinic, Cleveland, $\mathrm{OH}$ 44195, US.

E:somboot@ccf.org Twitter: @Dr_Whan

Support: No funding was received in the publication of this article.
$\mathrm{T}$ he American Epilepsy Society (AES) annual meeting took place in Washington DC in December 2017. In an expert interview, Thapanee Somboon discusses important results of an investigation she presented at the meeting into the effect of positive airway pressure (PAP) therapy on obstructive sleep apnea (OSA) in a retrospective series of patients with epilepsy.

\section{Q. How prevalent is obstructive sleep apnea (OSA) in people with epilepsy?}

OSA is a potentially serious disorder that occurs when a person's breathing is interrupted during sleep. It is associated with a number of health problems including hypertension, stroke, arrhythmias, heart failure, diabetes, obesity and sudden death. In addition, untreated OSA is commonly associated with daytime impairment that affects academic and occupational performance. OSA is one of the most common sleep disorders in the general population with a prevalence of roughly $24 \%$ in men and $9 \%$ in women. ${ }^{2}$ We previously reported a prevalence of $40 \%$ in people with epilepsy (PWE), including $16 \%$ with moderate-to-severe disease. ${ }^{3}$ The prevalence of OSA in children with epilepsy is unclear. As expected, middle-aged males are more susceptible than age-matched females, but the gender gap narrows significantly with advancing age. The prevalence of OSA does not appear to differ by epilepsy type (focal versus generalized) or seizure control (refractory versus controlled). ${ }^{4}$

\section{Q. How does the presence of OSA in epilepsy affect seizure control?} This issue remains unclear. Since sleep deprivation is a firmly established trigger for seizures and activation of epileptic discharges on electroencephalogram, it has been hypothesized that OSA would aggravate seizure control by producing a chronic state of sleep loss. Alternative mechanisms include sleep fragmentation, hypoxia, and associated cardiac arrhythmias, though they are unproven.

\section{Q. Could you tell us a little about positive airway pressure (PAP) therapy?}

PAP therapy is the preferred initial treatment for most people with OSA, particularly those with moderate-to-severe disease or significant comorbidities. PAP therapy delivers positive pressure to the airway during sleep that prevents airway collapse and the associated oxygen desaturations, heart rate changes, arousals and awakenings. Treatment is delivered through an interface in the nares or over the nose and/or mouth. Pressure requirements are determined either by auto- 
titrating devices in the home or titration study in the sleep laboratory. conservative treatments include weight loss, avoidance of sleeping on the back, which exacerbates airway closure, and avoidance of central nervous system-suppressing medications. Oral appliances, upper airway surgery and hypoglossal nerve stimulation therapy are alternatives to PAP in select cases. The role of OSA on sudden unexpected death in epilepsy (SUDEP) remains poorly elucidated. Since SUDEP occurs most often during sleep in the prone position, PWE should be educated about the importance of side sleeping.

\section{Q. What were the findings of your recent study investigating the long-term effect of PAP in epileptic patients with OSA?}

We investigated the effect of PAP therapy on seizure control in adults with epilepsy who underwent polysomnography (PSG) from 1997-2015. ${ }^{1}$ We collected demographic, epilepsy characteristic, PSG and PAP adherence data. Subjects were classified as having OSA on PAP therapy, OSA without PAP therapy (untreated) or not having OSA. We compared change in two seizure outcomes between groups from baseline to 1 year after diagnosis of OSA, and from baseline to the last available follow up. Seizure outcomes were responder rate $(\geq 50 \%$ seizure reduction if not seizure free over 6 months prior to PSG) and successful outcome (seizure free at both baseline and follow up or $\geq 50 \%$ reduction if not seizure free over 6 months prior to PSG). We controlled for antiepileptic drug (AED) standardized dose, a measure of drug burden, in order to eliminate the impact of drug change over time. At 1 year, responder rate was significantly greater in those with PAP-treated OSA (63\%; $p=0.001$ ) and no OSA (44\%; $p=0.023$ ) than untreated OSA (14\%). Successful outcome was more common in PAP-treated OSA $(85 \%)$ than untreated OSA $(55 \% ; p<0.001)$ or no OSA $(65 \% ; p=0.007)$. Findings were similar after 1 year; however, analyses were limited to small samples and were not significant.

\section{Q. What further research is needed in this area?}

Our study is an observational cohort from a single center. The only prospective, multi-center trial that explored the feasibility of treating OSA with PAP in adults with epilepsy was not powered to show treatmentassociated changes in seizures. ${ }^{5}$ Short of a multi-center, randomized controlled trial, which would be very challenging to fund in the current environment and with equipoise, more work needs to be done to: (1) extend these observations to pediatric patients; (2) confirm that beneficial effects extend to all patients, not just those with refractory epilepsy; and (3) educate epilepsy caregivers who are not trained in sleep medicine and may not be aware of OSA and other common sleep disorders that impact PWE. $\square$

\footnotetext{
1. Somboon T, Andrew N, Bena J, et al. Long-term seizure control in epileptic patients with obstructive sleep apnea using positive airway pressure therapy. Presented at: American Epilepsy Society (AES) Annual Meeting Washington DC, December 1-5, 2017. Abstr. 1.201. Available at: AES 2017 Annual Meeting Abstract Database, AESnet.org (accessed January 12, 2018).

2. Young T, Palta M, Dempsey J, et al. The occurrence of sleep-disordered breathing among middle-aged adults. N Eng/ J Med. 1993;328:1230-5.

3. Foldvary-Schaefer N, Andrews ND, Pornsriniyom D, et al. Sleep apnea and epilepsy: who's at risk? Epilepsy Behav. 2012;25:363-7.

Lin Z, Si Q, Xiaoyi Z. Obstructive sleep apnoea in patients with epilepsy: a meta-analysis. Sleep Breath. 2016;21:263-70.

5. Malow BA, Foldvary-Schaefer N Vaughn BV et al. Treating obstructive sleep apnea in adults with epilepsy: a randomized pilot trial. Neurology. 2008:71:572-7.
} 